\title{
Type of preoperative aura may predict postsurgical outcome in patients with temporal lobe epilepsy and mesial temporal sclerosis.
}

\author{
Ali Akbar Asadi-Pooya \\ Thomas Jefferson University \\ Maromi Nei \\ Thomas Jefferson University \\ Ashwini Sharan \\ Thomas Jefferson University \\ Michael R. Sperling \\ Thomas Jefferson University \\ Follow this and additional works at: https://jdc.jefferson.edu/neurologyfp \\ Part of the Neurology Commons \\ Let us know how access to this document benefits you
}

\section{Recommended Citation}

Asadi-Pooya, Ali Akbar; Nei, Maromi; Sharan, Ashwini; and Sperling, Michael R., "Type of preoperative aura may predict postsurgical outcome in patients with temporal lobe epilepsy and mesial temporal sclerosis." (2015). Department of Neurology Faculty Papers. Paper 107. https://jdc.jefferson.edu/neurologyfp/107

This Article is brought to you for free and open access by the Jefferson Digital Commons. The Jefferson Digital Commons is a service of Thomas Jefferson University's Center for Teaching and Learning (CTL). The Commons is a showcase for Jefferson books and journals, peer-reviewed scholarly publications, unique historical collections from the University archives, and teaching tools. The Jefferson Digital Commons allows researchers and interested readers anywhere in the world to learn about and keep up to date with Jefferson scholarship. This article has been accepted for inclusion in Department of Neurology Faculty Papers by an authorized administrator of the Jefferson Digital Commons. For more information, please contact: JeffersonDigitalCommons@jefferson.edu. 
Title: Auras may predict postsurgical outcome in patients with temporal lobe epilepsy and mesial temporal sclerosis.

\author{
Ali A. Asadi-Pooya, M.D., Maromi Nei, M.D., Ashwini Sharan, M.D., Michael R. Sperling, \\ M.D. \\ Jefferson Comprehensive Epilepsy Center, Department of Neurology, Thomas Jefferson \\ University, Philadelphia, Pennsylvania, U.S.A.
}

\title{
Address for correspondence:
}

Ali A. Asadi-Pooya, M.D.

Department of Neurology

901 Walnut Street, Suite 435

Philadelphia, PA 19107

Phone: 215-955-1222

Fax: 215-955-3745

E-mails: aliasadipooya@yahoo.com; michael.sperling@jefferson.edu;

maromi.nei@jefferson.edu; ashwini.sharan@jefferson.edu

Key words: Aura; Surgery; Temporal lobe epilepsy.

Running title: Auras may predict postsurgical outcome.

Word count for the paper: 2346. Word count for the abstract: 208. Number of pages: 6 .

Number of references: 13 .

Number of tables: 1 .

Number of figures: 2 . 


\begin{abstract}
:
Purpose: As the initial symptoms of epileptic seizures, many types of auras have significant localizing or lateralizing value. In this study, we hypothesized that the type of aura may predict postsurgical outcome in patients with medically refractory temporal lobe epilepsy (TLE) and mesial temporal sclerosis (MTS).
\end{abstract}

Methods: In this retrospective study all patients with a clinical diagnosis of medically refractory TLE due to unilateral mesial temporal sclerosis who underwent epilepsy surgery at Jefferson comprehensive epilepsy center were recruited. Patients were prospectively registered in a database from 1986 through 2014. Post-surgical outcome was classified into two groups; seizurefree or relapsed. Outcome was compared between seven groups of patients according to their preoperative auras.

Results: Two hundred thirty-seven patients were studied. The chance of becoming free of seizures after surgery in patients with abdominal aura was $65.1 \%$, while in other patients this was 43.3\% $(\mathrm{P}=0.01)$. In two by two comparisons, no other significant differences were observed. Conclusion: Patients with medically-refractory TLE-MTS, who reported abdominal auras preceding their seizures, fared better postoperatively with regard to seizure control compared to those who did not report auras, which may indicate bitemporal dysfunction, and to patients with other auras, which may indicate a widespread epileptogenic zone in the latter group of patients.

Key words: Aura; Surgery; Temporal lobe epilepsy. 


\section{Introduction}

Aura is a subjective ictal phenomenon that may precede an observable seizure ${ }^{1}$. Auras constitute a cardinal feature of temporal lobe epilepsy (TLE), which is the most common type of focal epilepsy in adults ${ }^{2}$. Mesial temporal sclerosis (MTS) is the most common pathological abnormality associated with TLE $^{3}$. The long-term prognosis of pharmacological therapy in patients with TLE-MTS is generally poor ${ }^{4}$, but surgery is a valuable therapeutic option in these patients. Surgery is superior to medical treatment alone in patients with TLE and drug-resistant seizures ${ }^{5}$. However, despite the significant improvement in the evaluation of potential surgical candidates, the success of epilepsy surgery in patients with TLE-MTS and medically-refractory seizures has not remarkably changed in recent decades ${ }^{6}$.

The goal of the presurgical evaluation in potential surgical candidates is to identify the epileptogenic zone, the cortical area generating seizures, the complete removal of which is necessary for seizure freedom. However, no clinical information or diagnostic method directly and definitively assesses the location and extent of the epileptogenic zone ${ }^{7}$. In this context, multiple sources of data [e.g., history and semiology of seizures, electroencephalography (EEG), imaging and functional assessments] help define the presumptive epileptogenic zone.

As the initial symptoms of epileptic seizures, many types of auras have significant localizing or lateralizing value ${ }^{7}$. In this study, we hypothesized that the type of aura may predict postsurgical outcome in patients with medically refractory temporal lobe epilepsy and mesial temporal sclerosis. 


\section{Methods}

In this retrospective study, all patients with a clinical diagnosis of medically refractory TLE due to unilateral mesial temporal sclerosis who underwent epilepsy surgery at Jefferson comprehensive epilepsy center were recruited. Patients were prospectively registered in a database from 1986 through 2014. The diagnosis of TLE-MTS was made by the epileptologists working at this institution and based on clinical grounds (semiology), electroencephalographic (EEG) findings and imaging [magnetic resonance imaging (MRI)]. There was no age limit to enter the study. For all patients, a comprehensive presurgical evaluation including a 1.5 Tesla brain MRI (epilepsy protocol) was performed. Magnetic resonance imaging studies were analyzed by neuroradiologists with expertise in epilepsy. We classified patients as having MTS if they had clear signs of mesial temporal atrophy and/or sclerosis in their MRI. Patients with normal MRI and those with bilateral MTS or dual pathology and also, patients with concomitant psychogenic non-epileptic seizures were excluded from this study.

All patients had an anterior temporal lobectomy and had a minimum of one year followup. We followed the patients for up to 5 years (in many patients the data was missing beyond five years of follow-up). Post-surgical outcome was classified into two groups; seizure-free or relapsed. Aura was not considered as a relapse; only postoperative tonic-clonic seizures and complex partial seizures were considered as relapse.

Age, gender, age at seizure onset (i.e., the first afebrile seizure), seizure type(s), EEG findings and MRI findings, date of surgery, date of the first relapse (if any) and date of the last contact with all patients were registered routinely. Outcome was compared between seven groups of patients, according to their preoperative auras. The first group included patients with abdominal aura (abdominal discomfort including nausea, emptiness, tightness, butterflies, 
malaise, pain, or hunger; sensation may rise to chest or throat); the second group included patients with auditory aura (buzzing, drumming sounds or single tones); the third group of patients reported affective auras (i.e., fear, anxiety, depression, joy, or anger); the fourth group reported mnemonic auras [i.e., feelings of familiarity (déjà-vu) or unfamiliarity (jamais-vu)]; the fifth group had other types of auras (e.g., sensory, visual, etc.); the sixth group reported multiple types of auras; and finally, the last group did not report an aura preceding their seizures.

Demographic variables and relevant clinical variables were summarized descriptively to characterize the study population. Pearson Chi-Square and Mantel-Cox tests were used for statistical analyses. Time to event analysis was used to produce a Kaplan-Meier estimate of seizure recurrence. Relative risk and $95 \%$ confidence interval (CI) were calculated. P value less than 0.05 was considered as significant. This study was conducted with the approval by Thomas Jefferson University Review Board. 


\section{Results}

Two hundred thirty-seven patients were studied (115 male and 122 females). Age at surgery was $36.9 \pm 11.8$ years. Sixty-three patients $(26.6 \%)$ reported no auras, while 43 persons $(18.1 \%)$ reported abdominal aura, $14(5.9 \%)$ had affective aura, $11(4.6 \%)$ reported mnemonic aura, $9(3.8 \%)$ had auditory aura, $46(19.4 \%)$ had other types of auras and $51(21.5 \%)$ patients had multiple types of auras preceding their seizures, preoperatively. The patients were followed for $4.3 \pm 1.1$ years (minimum 1 and maximum 5 years). One hundred and twelve patients (47.3\%) remained seizure-free until their last follow-up, and 125 people (52.7\%) experienced one or more seizures after their surgery. The chance of postoperative seizure recurrence had a significant association with the type of aura the patients had reported preoperatively (Table 1). The chance of becoming free of seizures after surgery in patients with abdominal aura was $65.1 \%$, while in those with no aura or other types of auras this chance was $43.3 \%(\mathrm{P}=0.01)$ (Figure 1). The relative risk of postoperative seizure recurrence in patients with abdominal aura compared with those with no aura or other types of auras was 0.6 (95\% CI: 0.4-0.94). In two by two comparisons, no other significant differences were observed. Even when we grouped abdominal, affective and mnemonic auras together (as temporal auras) and compared them with other patients, the difference in postsurgical outcome was not significant $(\mathrm{P}=0.057)$. Similarly, those with no aura did not have a significantly different postsurgical outcome compared with the whole group of patients who reported an aura; the seizure-free rate in patients with no aura was $41.3 \%$ and in patients with an aura was $49.4 \%(\mathrm{P}=0.1)$ (Figure 2). 


\section{Discussion}

As the first ictal symptoms, auras can provide important localizing and lateralizing information useful in determining the location of the epileptogenic zone ${ }^{7}$. Abdominal auras constitute the most common type of autonomic auras. These include sensations of nausea, pain, or indescribable discomfort in the abdominal or periumbilical area that can be static, rise to the chest and throat, or descend into the lower abdominal region. In the current study, presence of abdominal aura was a good prognostic indicator for seizure-free outcome after temporal lobectomy in patients with TLE-MTS. In a previous study, the seizures of 491 consecutive patients with focal epilepsies were prospectively classified. Abdominal auras were more frequent with TLE (117 of 223 patients, 52\%) than in extratemporal epilepsy (13 of 113 patients, 12\%, p $<0.0001$ ), and more frequent in mesial TLE (70 of 110 patients, 64\%) than in neocortical TLE (16 of 41 patients, $39 \%, p=0.007$ ). The authors concluded that an abdominal aura is associated with TLE with a probability of $73.6 \%$. The evolution of an abdominal aura into an automotor seizure, however, increases the probability of TLE to $98.3 \%{ }^{8}$. In a previous study of 58 patients who had temporal lobectomy for seizure control, epigastric rising sensations were associated with a greater chance of a good outcome than were other forms of auras ${ }^{9}$. However, in a recent study of 331 temporal lobe epilepsy patients who received surgical treatment, the authors found that abdominal auras with or without rising sensations did not predict postoperative seizure outcome ${ }^{10}$. In these studies, the authors included all patients with TLE (i.e., mesial temporal sclerosis, tumors, vascular lesions, etc.) that might confound the findings.

In the current study, lack of an aura was not a poor prognostic indicator for seizure-free outcome compared with the group of patients with an aura of any type, but patients without aura fared worse than those with an abdominal aura. In one study, the authors found that lack of aura 
experience strongly correlates with indicators of bitemporal dysfunction ${ }^{11}$. However, this is a different study population. While lack of aura could be evidence of bitemporal dysfunction, it could also be due to other reasons (e.g., a larger epileptogenic zone ipsilaterally). Besides, since this is a retrospective study, we are limited by reporting bias. In another study the significance of the latter finding was indirectly highlighted, when the characteristics and prognostic significance of subclinical seizures and independent auras were studied in 40 patients with partial epilepsy. Subclinical seizures and auras were of favorable prognostic significance for patients undergoing temporal lobectomy. A majority (>80\%) of individuals with subclinical seizures and auras were free of complex partial seizures after surgery, whereas a minority (29\%) of patients without subclinical seizures and auras became free of complex partial seizures ${ }^{12}$. In another study, the authors reviewed video recordings of 130 adult patients who had undergone epilepsy surgery for intractable medial temporal lobe epilepsy ${ }^{13}$. All patients were instructed to push the alarm button when they felt an aura. They defined the preictal reactivity as the ability to push the alarm button before the complex partial (unconscious) phase of seizures. Seventy-seven patients (59\%) pushed the alarm button before seizures. Patients with preictal reactivity had a better postoperative outcome. Patients who did not push the alarm button had more frequent secondarily generalized seizures. They concluded that the ability to react before a complex partial seizure is associated with a circumscribed region involved at seizure onset and spread, and with a better outcome postoperatively ${ }^{13}$.

Finally, as auditory auras are produced by activation of the primary auditory cortex or auditory association areas in the temporo-occipital cortex ${ }^{7}$, their presence in a patient with TLEMTS may herald a more widespread epileptogenic zone; this theoretically decreases the chance of seizure freedom after a standard temporal lobectomy for MTS. This hypothesis also applies to 
other auras, which are produced by non-mesial temporal structures. In the current study, we observed that patients with medically-refractory TLE-MTS, who reported abdominal auras preceding their seizures, fared better postoperatively with regard to seizure control compared to those with auditory auras or other types of auras (Table 1).

\section{Conclusion}

The goal of the presurgical evaluation in potential surgical candidates is to identify the epileptogenic zone. However, no clinical information or diagnostic method directly and definitively assesses the location and extent of the epileptogenic zone ${ }^{7}$. In this context, many pieces of information help make a hypothesis as where the epileptogenic zone is located. As the first ictal symptoms, auras can provide important localizing and lateralizing information useful in determining the location of the epileptogenic zone ${ }^{7}$. In the current study, we observed that patients with medically-refractory TLE-MTS, who reported abdominal auras preceding their seizures, fared better postoperatively with regard to seizure control compared to those who did not report auras, which probably indicates a bitemporal dysfunction, or patients with other auras, which probably indicates a widespread epileptogenic zone in these patients. 


\section{Conflict of interest}

Ali A. Asadi-Pooya, M.D., reports no disclosures.

Maromi Nei, M.D., Research: Upsher-Smith Laboratories.

Ashwini Sharan, M.D., Consulting, Clinical Trial Site - Medtronic; SJM, Clinical Trial

Site - Grant, honorarium; ICVRX - ownership interest; ICP - ownership interest; Tiger labs ownership interest; Saluda Medical - Clinical Trial Site.

Michael R. Sperling, M.D., Consulting: UCB Pharma; Research: contracts with Thomas Jefferson University, Eisai, UCB Pharma, Sunovion, SK Life Sciences, Marinus, Lundbeck, Medtronics, Visualase, Accorda, Upsher-Smith, Brain Sentinel.

\section{Acknowledgment}

This was a non-funded study. 


\section{Reference}

1. Blume WT, Lüders HO, Mizrahi E, et al. Glossary of descriptive terminology for ictal semiology: report of the ILAE task force on classification and terminology. Epilepsia 2001; 42(9): 1212-1218.

2. Téllez-Zenteno JF, Hernández-Ronquillo L. A review of the epidemiology of temporal lobe epilepsy. Epilepsy Res Treat 2012; 2012: 630853.

3. Babb, T.L., Brown, W.J., 1987. Pathological findings in epilepsy. In: Engel Jr., J. (Ed.), Surgical Treatment of the Epilepsies. Raven Press, New York, pp. 511-540.

4. Kumlien E, Doss RC, Gates JR. Treatment outcome in patients with mesial temporal sclerosis. Seizure 2002; 11(7): 413-417.

5. Engel J Jr, McDermott MP, Wiebe S, et al; Early Randomized Surgical Epilepsy Trial (ERSET) Study Group. Early surgical therapy for drug-resistant temporal lobe epilepsy: a randomized trial. JAMA 2012; 307(9): 922-930.

6. Ferrari-Marinho T, Caboclo LO, Marinho MM, et al. Auras in temporal lobe epilepsy with hippocampal sclerosis: relation to seizure focus laterality and post-surgical outcome. Epilepsy Behav 2012; 24(1): 120-125.

7. Foldvary-Schaefer N, Unnwongse K. Localizing and lateralizing features of auras and seizures. Epilepsy Behav 2011; 20(2): 160-166.

8. Henkel A, Noachtar S, Pfander M, et al. The localizing value of the abdominal aura and its evolution: a study in focal epilepsies. Neurology 2002; 58: 271-276.

9. Duncan JS, Sagar HJ. Seizure characteristics, pathology, and outcome after temporal lobectomy. Neurology 1987; 37(3): 405-409. 
10. Kuan YC, Shih YH, Chen C, et al. Abdominal auras in patients with mesial temporal sclerosis. Epilepsy Behav 2012; 25(3): 386-390.

11. Schulz R, Lüders HO, Hoppe M, et al. Lack of aura experience correlates with bitemporal dysfunction in mesial temporal lobe epilepsy. Epilepsy Res 2001; 43(3): 201-210.

12. Sperling MR, O'Connor MJ. Auras and subclinical seizures: characteristics and prognostic significance. Ann Neurol 1990; 28: 320-328.

13. Gyimesi C, Fogarasi A, Kovács N, et al. Patients' ability to react before complex partial seizures. Epilepsy Behav 2007; 10(1): 183-186. 
Figure 1 legend. Postoperative seizure outcome was significantly better in patients with abdominal aura compared to those with other auras $(\mathrm{P}=0.01)$.

Figure 2 legend. Postoperative seizure outcome was not significantly different in patients with an aura compared to those with no auras $(\mathrm{P}=0.1)$. 